\title{
Studies on fire behavior in a confined compartment based on reduced-scale experiment Jin Zhou ${ }^{a}$, Jinfeng Maob ${ }^{b}$ Yuliang Huang ${ }^{c}$ and Zheli Xing ${ }^{d}$
}

College of Defense Engineering, PLA University of Science and Technology, Nanjing, Jiangsu, China

a mingmeng.2006@163.com, b maojinfeng628@sina.com, ${ }^{c}$ yulianghuang84@sina.com, d zheli86@sina.com

Keywords: Fire behavior, Confined compartment, Reduced-scale experiment

Abstract. A reduced-scale compartment model was built to investigate the fire behavior in a confined compartment. Three different sizes of pool fire were involved in this study. And the fire behaviors in open space were also studied to compare with which in the confined compartment. The results shows the fire in confined space associated with larger pool exhibits a sharper growth and decrease in mass burning rate(MBR); meanwhile, a larger pool led to higher top MBR. When compare the fires in confined space with open space, the fires in open space got their top burning rate earlier, and they exhibited stronger and more frequent fluctuation. The influence brought by confined compartment on the fire was more pronounced in smaller pool fire. The processes of heat release rate (HRR) in confined compartment was also obtained.

\section{Introduction}

The fire behavior in a confined compartment was different from which in open space. The fire will be affected by the envelope structure, ventilation and etc.. In recent years, a great number of studies were carried out to study the fire behavior in confined compartment ${ }^{[1-7]}$. Previous studies shows that the fire behavior in confined compartment is extremely complicated, and the results obtained under different circumstance even seems contradictory. The results from Hugues et al. ${ }^{[8]}$ shows the burning rate in confined compartment excesses the burning rate in open space. However, Sugawa et al. ${ }^{[9]}$ got a contradictory conclusion from their studies which exhibited the burning rate in confined space is much less than open space.

In this study, a series of experiment were conducted to investigated fire behavior associated with different sizes of pool in confined compartment.

\section{Experiment}

\section{Scaling rule}

To relate the reduce-scale model to the full-scale, three critical non-dimensional parameters, as followings, were selected to be equal ${ }^{[10]}$.

$$
\begin{aligned}
& \pi_{1}=\frac{L}{v \tau}=\frac{\sqrt{L / g}}{\tau} \\
& \pi_{2}=\frac{g L}{v^{2}} \\
& \pi_{3}=\frac{Q}{\rho_{0} c_{p} g^{1 / 2} T_{0} H^{5 / 2}}
\end{aligned}
$$

where $\pi$ is the non-dimensional parameter, $\mathrm{L}$ is the characteristic length, $\mathrm{v}$ is the characteristic velocity, $\mathrm{g}$ is the gravity acceleration, $\tau$ is the time, $\rho$ is the ambient density, $Q$ is the heat release rate(HRR). Subscript 0 relates ambient parameter.

By equaling the three non-dimensional parameters mentioned above, the parameters between reduced-scale model and full-scale are as follows: 


$$
\begin{aligned}
& \frac{Q_{m}}{Q_{f}}=\left(\frac{L_{m}}{L_{f}}\right)^{5 / 2} \\
& \frac{\tau_{m}}{\tau_{f}}=\left(\frac{L_{m}}{L_{f}}\right)^{1 / 2} \\
& \frac{T_{m}}{T_{f}}=1
\end{aligned}
$$

where subscript $m$ relates to model scale, and subscript $f$ relates to full scale.

\section{Model}

A 1:4 reduced-scale model was prepared to study the fire behavior in confined compartment. Figure 1 shows the layout of the model. The compartment is $1.2 \mathrm{mlong}, 0.75 \mathrm{~m}$ wide and $0.6 \mathrm{~m}$ tall, which connected to a corridor by a door. One end of the corridor, which near the compartment, is close; while the other end is open. The whole model, except the ceil of compartment, was made of toughened glass in order to observe the flame. The ceil of compartment was made of galvanized iron.

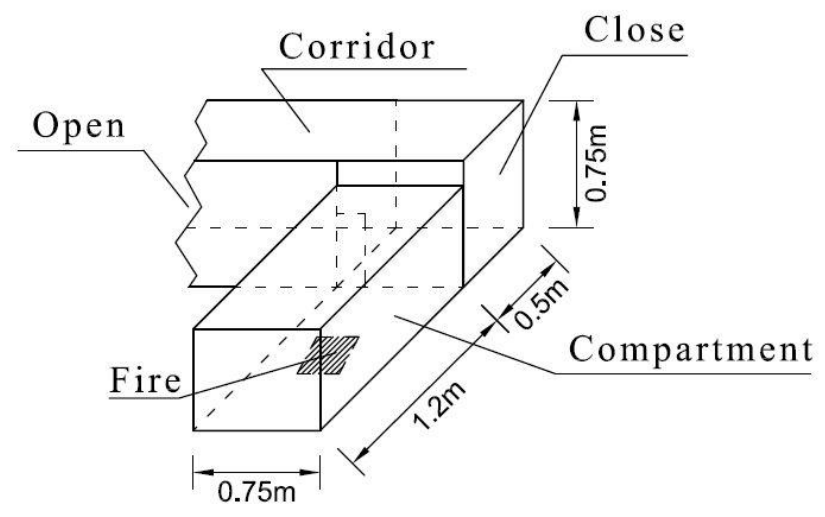

(a) The schematic layout of the model

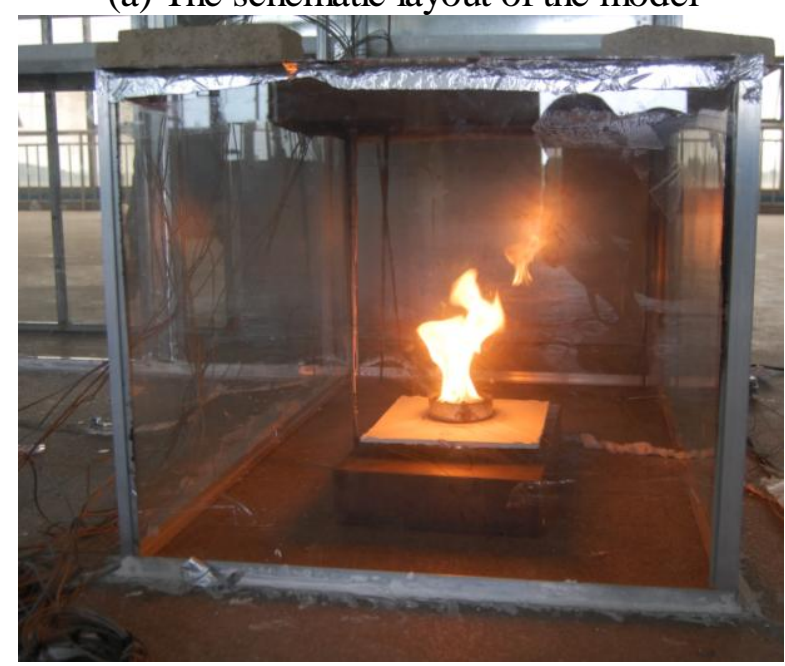

(b) The photograph of the model

Figure 1. The schematic layout and the photograph of the model

An ironed pool with fuel of heptane was used as fire source. The tray was located in the center of room floor. To study the effect of variant HRR, three different sizes of tray with variant volume of fuel, as can be seen from Table 1, were involved in this study. 
Table 1

\begin{tabular}{ccc}
\hline & Diameter(mm) & Volume $(\mathrm{ml})$ \\
\hline Case A & 100 & 100 \\
Case B & 140 & 200 \\
Case C & 200 & 300 \\
\hline
\end{tabular}

\section{Measurement}

The mass loss rate of the fuel was measured by electronic scale with extra precision. The data from the electronic scale was transferred to the computer via cable. The electronic scale was covered by an iron box and the fuel pool was putted on the fireproofing material to protect the electronic scale from the damage of the fire. The cable connect the electronic scale and computer was covered by fireproofing fabric. All the fireproofing measures can be seen in Fig. 1(b).

\section{Analysis}

\section{Mass burning rate}

Mass burning rate(MBR) is a very critical parameter to the HRR of the fire. The MBRs in confined compartment are plotted against time as shown in Fig. 2, for three sizes of tray. The result shows the fire associated with pool of $100 \mathrm{~mm}$ diameter exhibits a smooth growth and decrease; while, the fire associated with pool of $200 \mathrm{~mm}$ diameter exhibits a sharp growth and decrease. The fire associated with pool of $200 \mathrm{~mm}$ diameter got its top MBR earlier compared with the other two pools; meanwhile, its top value was much higher.

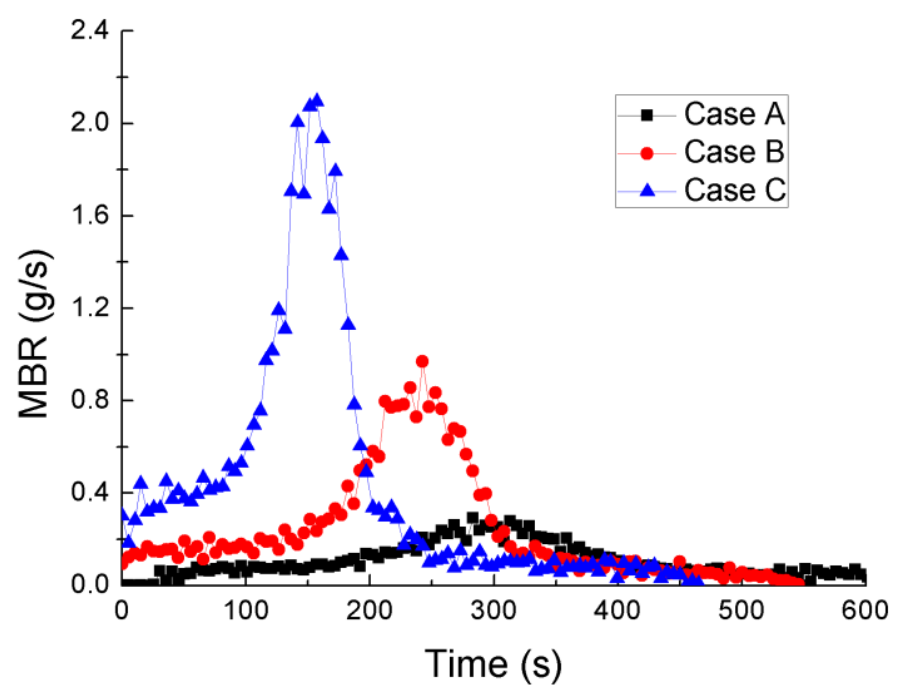

Figure 2. The mass burning rates versus time in confined space

\section{Comparison between confined space and open}

Fig. 3 shows the comparison of MRB between confined space and open. For all three cases, the fires in open space got their top burning rate earlier compared with which in confined compartment, and they exhibited stronger and more frequent fluctuation. The influence brought by confined compartment on the fire was more pronounced in smaller pool fire. 


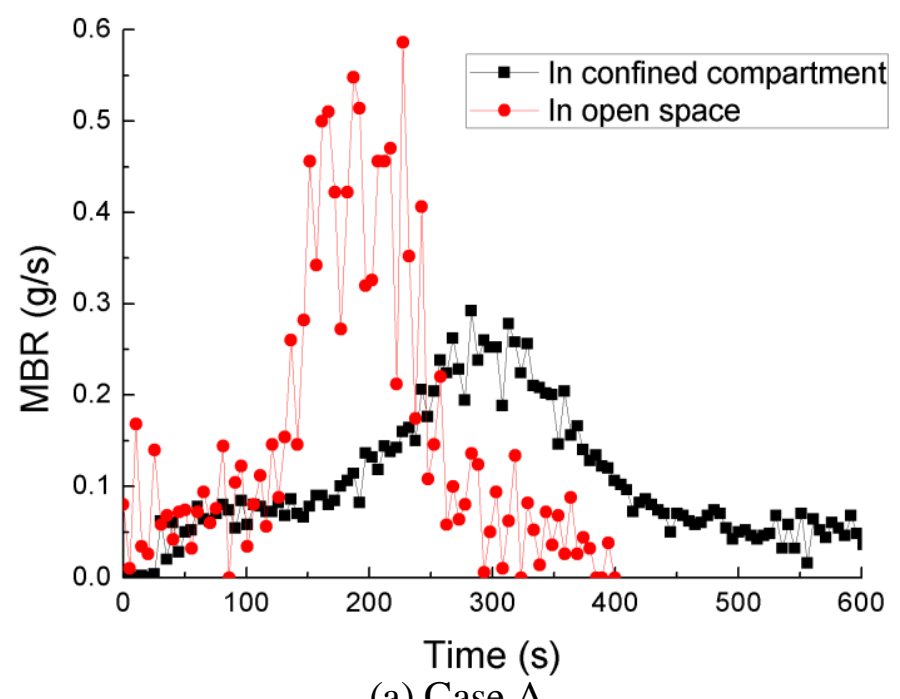

(a) Case $\mathrm{A}$

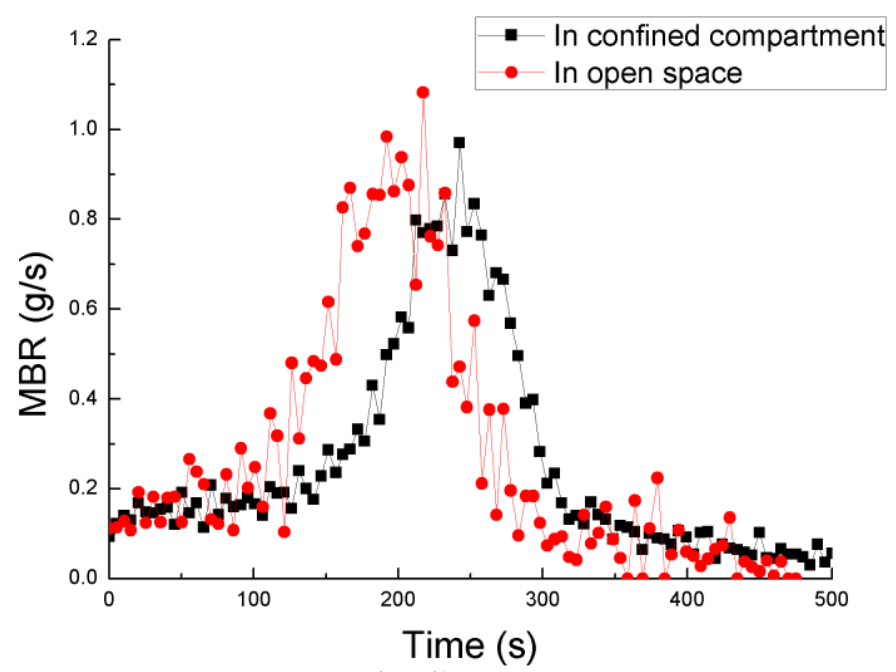

(b) Case B

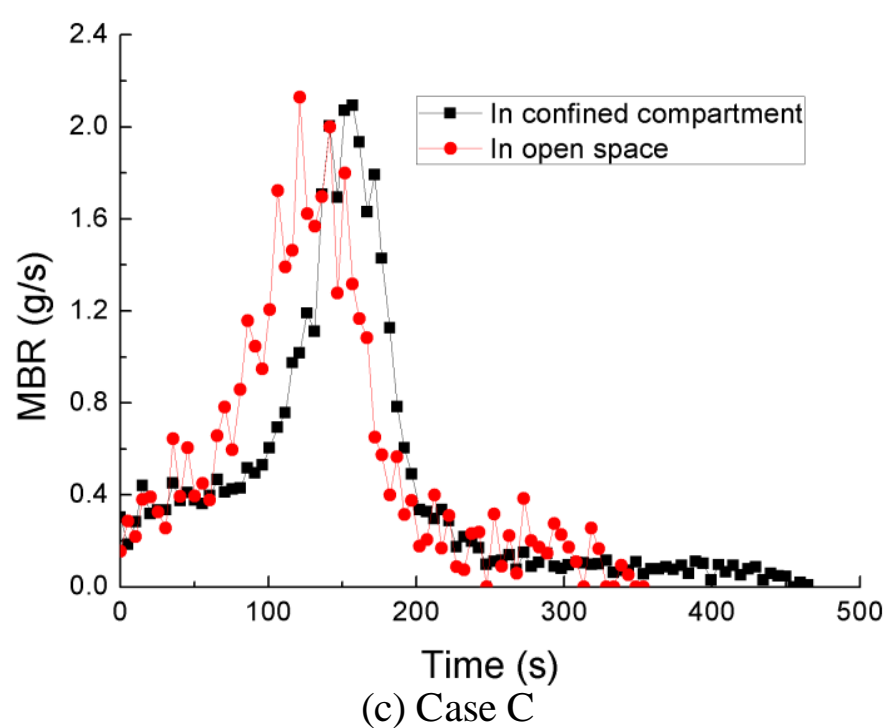

Figure 3. The comparison between confined space and open

In order to investigate the whole process of MBR, the average MBR was introduced, which is defined as follows:

$$
\overline{\dot{m}}=\left(\int_{o}^{\tau_{E}} \dot{m} d \tau\right) / \tau_{E}
$$

Table 2 shows the comparison of the average MRB between confined space and open. 
Table 2 The comparison of the average MRB

\begin{tabular}{c|c|c|c}
\hline \multirow{2}{*}{ Case } & $\begin{array}{c}\text { confined space } \\
\overline{\dot{m}}_{\text {confined }}(\mathrm{g} / \mathrm{s})\end{array}$ & open space $\overline{\dot{m}}_{\text {open }}(\mathrm{g} / \mathrm{s})$ & $\overline{\dot{m}}_{\text {confined }} / \overline{\dot{m}}_{\text {open }}$ \\
\hline $\mathrm{A}$ & 0.0998 & & $63.97 \%$ \\
$\mathrm{~B}$ & 0.231 & 0.156 & $74.52 \%$ \\
$\mathrm{C}$ & 0.424 & 0.319 & $75.18 \%$ \\
\hline
\end{tabular}

As can seen from the table, the average MBR increase as the pool size increases, for both confined space and open space. Meanwhile, the average MBR percentages of confined space to open are $63.97 \%, 74.52 \%$, and $75.18 \%$ respectively. It means average MBR percentage of confined space to open shows an increase as the pool size increases.

\section{HRR}

The HRR was calculated by using the following formula

$Q=\lambda \dot{m} h_{c}$

where $\lambda$ is the combustion efficiency, $h_{c}$ combustion heat.

The combustion efficiency $\lambda$ can be calculated by using the following formula

$$
\lambda=0.284 \rho_{g} V_{g} \dot{Y}_{o x} / \dot{m}
$$

where $\rho_{g}$ is the gas density, $V_{g}$ is the volume of the gas, $\dot{Y}_{o x}$ is the variation rate of oxygen mass fraction, $\dot{m}$ is the MBR. $\dot{Y}_{o x}$ and $\dot{m}$ took averages of the process when calculating.

The HRRs versus time for three cases were plotted in Fig. 4. The trend of HRRs obtained from the calculation shows similarity with the MBRs.

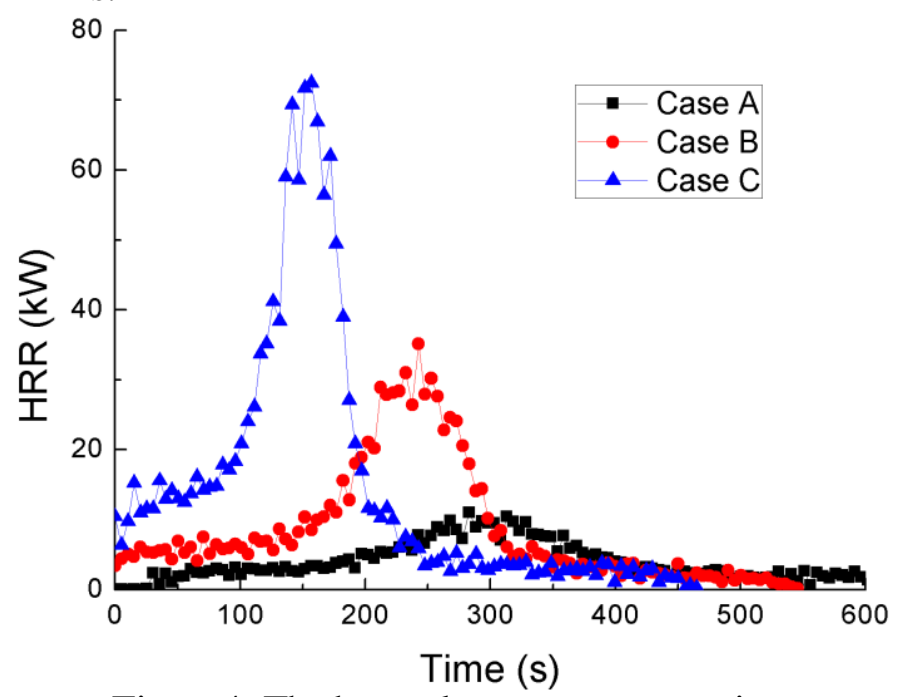

Figure 4. The heat release rates versus time

\section{Conclusion}

A 1:4 reduced-scale model was prepared to study the fire behavior in confined compartment.

The fire in confined space associated with larger pool exhibited a sharper growth and decrease in MBR; meanwhile, a larger pool led to higher top MBR.

When compare the fires in confined space with open space, the fires in open space got their top burning rate earlier compared with which in confined compartment, and they exhibited stronger and more frequent fluctuation. The influence brought by confined compartment on the fire was more pronounced in smaller pool fire.

As for three cases, the average MBR percentages of confined space to open are $63.97 \%, 74.52 \%$, and $75.18 \%$ respectively, which means he average MBR percentage of confined space to open increases as the pool size increases. 


\section{Acknowledgement}

The authors greatly acknowledge the PLA University of Science and Technology for its support.

\section{References}

[1] Y. Utiskul, J. Ouintiere, A. Rangwala, Compartment fire phenomena under limited ventilation. Fire Saf. J. 40 (2005) 367-390.

[21 A. Pearson, J. Most, D. Drysdale, Behavior of a confined fire located in an unventilated zone. P. Combust. Inst. 31 (2007) 2529-2536.

「3] Z. Hu, Y. Utiskul, J.G. Quintiere, A. Trouve, Towards large eddy simulations of flame extinction and carbon monoxide emission in compartment fires. P. Combust. Inst. 31 (2007) 2537-2545.

$\lceil 41$ A. Nasr, S. Suard, H. El-Rabii, J. P. Garo, L. Gay, L. Rigollet, Heat feedback to the fuel surface of a pool fire in an enclosure. Fire Saf. J. 60 (2013) 56-63.

[5] Y.C. Wu, X.C. Wu, S.X. Lu, C.H. Li,. Flame pulsation modes of pool fire in confined compartment with single ceiling opening. J. Combust. Sci. Tech. 17 (2011) 425-431.

「6] S. Li, R. Zong, L. Chen, T. Wei, G. Liao, S. Li, Effect of different fuels on confined compartment fire. J. Fire Sci. 28(2010), 4, 383-403.

I7] P.H. Zhang, X.W. Lu, X.M. Zhang, Numerical simulation on ghosting fire in the confined underground space. Advances in Civil \& Industrial Engineering IV. 2014

[81 H. Pretrel, P. Querre, M. Forestier, Experimental study of burning rate behavior in confined and ventilated fire compartments. Fire Sci.Technology.8 (2006) 1217-1228

[9] O. Sugawa, K. Kawagoe, Y. Oka, Burning behavior in a poor-ventilation compartment fire-ghosting fire . Nuclear Engineering \& Design, 125 (1991) 347-352.

[10]B. Karlsson, J.G. Quintiere, Enclosure Fire Dynamics, CRC Press, New York, 2000 